\title{
Contextualização, Experimentação e a Pesquisa na Web para Despertar o Interesse pelo Estudo das Reações Químicas
}

\author{
Contextualization, Experimentation and Search the Web for Wake Interest in the Study of \\ Chemical Reactions \\ Da Silva, J. R. ; Melo, M. R. ${ }^{1,2}$; \\ ${ }^{1}$ Programa de Pós-Graduação em Ensino de Ciências e Matemática (PPGECIMA), Universidade Federal de Sergipe, \\ 49100-000, São Cristóvão-SERGIPE, Brasil. \\ ${ }^{21}$ Universidade Federal do Rio Grande (FURG), 96170-000, São Lourenço do Sul, Rio Grande do Sul, Brasil \\ *profjaimersilva@oi.com.br
}

(Recebido em 31 de outubro de 2015; aceito em 29 de outubro de 2016)

\begin{abstract}
Os estudantes que estão na transição do ensino fundamental para o médio, encontram dificuldades para compreender os conteúdos das Ciências, pois trazem consigo algumas concepções errôneas sobre conceitos. $\mathrm{Na}$ busca de alternativas, ao ensino bancário, trabalhamos com três eixos de mediação do conhecimento: a contextualização, a experimentação e as situações de estudo. O projeto intitulado "A importância do estudo das Reações Químicas para a prática cidadã", desenvolvido com os alunos do nono ano do ensino fundamental, envolveu 21 aulas durante sete semanas e contou com a participação de 34 alunos do ano letivo de 2014. A separação do projeto em etapas, permitiu organizar o trabalho acadêmico e motivar o grupo para as fases seguintes. $\mathrm{O}$ objetivo foi desenvolver experimentos simples em sala de aula, com o suporte da contextualização e usando situações de estudo (SE) investigativas, para explicar e chamar a atenção para o estudo das reações químicas, assim como, de inserir os alunos na cultura científica.

Palavras-chave: Contextualização; Experimentação; Pesquisa.
\end{abstract}

Students who are in the transition from elementary school to the average, find it difficult to understand the content of science, because they bring with them some misconceptions about concepts. In the search for alternatives to the banking education, we work with three axes of knowledge mediation: contextualization, experimentation and study situations. The project entitled "The importance of the study of chemical reactions for citizen practice" developed with students from the ninth grade of elementary school, involved 21 classes for seven weeks and included the participation of 34 students of the school year 2014. Separation the project in stages, allowed the organization of academic work and motivate the group to the next stages. The goal was to develop simple experiments in the classroom, with the support of context and using study situations (SE) investigative, to explain and draw attention to the study of chemical reactions, as well as entering students in scientific culture.

Keywords: Contextualization; Experimentation; Research.

\section{INTRODUÇÃO}

Os alunos que cursam o nono ano do ciclo básico, correspondente a última etapa do ensino fundamental, e que futuramente ingressarão no Ensino Médio, trazem consigo a ideia de que a Química é uma ciência difícil e complicada. Soma-se a essa visão o modo de ensinar de alguns professores, que cria obstáculos ao aprendizado da disciplina e até na permanência dos estudantes na unidade escolar.

Os problemas que envolvem o ensino de ciências nas escolas do Brasil são grandes, no entanto, aqueles que tratam de ensino e aprendizagem são predominantes. O método tradicional de ensino e vinculado à uma educação bancária, descrita por Freire [1] e conhecida por "frases de efeito", como, por exemplo, o "educador é o sujeito do processo e os educandos meros objetos", não é capaz de formar cidadãos críticos, mas sim sujeitos desligados dos fenômenos reais. Isso se deve, a busca constante pela memorização dos conteúdos, que impede a construção de situações na sala de aula que contribuam para a reflexão da condição que vive os aprendizes no dia a dia. O ensino bancário, para o qual a educação é o ato de depositar, de transferir, de transmitir valores e conhecimentos, reflete a sociedade opressora, da cultura do silêncio e que estimula a contradição. 
Na concepção bancária o educador é o que sabe e os educandos, os que não sabem; o educador é o que pensa e os educandos, os pensados; o educador é o que diz a palavra e os educandos, os que escutam docilmente; o educador é o que opta e prescrevem sua opção e os educandos, os que seguem a prescrição; o educador escolhe o conteúdo programático e os educandos jamais são ouvidos nessa escolha e se acomodam a ela; o educador identifica a autoridade funcional, que the compete, com a autoridade do saber, que se antagoniza com a liberdade dos educandos, pois os educandos devem se adaptar às determinações do educador; e, finalmente, o educador é o sujeito do processo, enquanto os educandos são meros objetos (GADOTTI, 1989. p. 69).[2]

A educação de hoje cobra dos professores o uso de questões problematizadoras, nas quais os alunos tenham condições de melhor compreender os aspectos da constituição, das propriedades e das transformações dos materiais, segundo defendem Mortimer, Machado e Romanelli [3]. O uso destas questões, como alternativa aos exercícios repetitivos, também é defendida por Batinga e Teixeira [4]:

A proposição e abordagem de problemas pelo professor não se constitui numa tarefa fácil de ser concebida e realizada no contexto escolar. Por isso, insistimos na necessidade de que fique claro para o professor a distinção entre o conceito e as características de um exercício e problema, para que ele se conscientize de que a estratégia de RP (Resolução de Problemas) exige algo mais do aluno do que o simples exercício com ênfase na repetição.

Nas escolas a rotina de memorizar conteúdos descontextualizados da vida do aluno persiste, apesar dos professores terem conhecimento que após as provas os assuntos desenvolvidos por eles, são facilmente esquecidos [5]. Esses docentes dificilmente entendem que essa postura contribui não só para o desinteresse dos estudantes pelo ensino e o estudo, como também agrava a sua frustração como profissional da educação. No entanto, alguns reconhecem que quando os aprendizes são questionados e desafiados, preferem participar das atividades do que receber as informações de maneira pronta [6,7].

A atual forma de transmitir conhecimentos nas escolas não prepara, na maioria das vezes, alunos para um futuro que está constantemente em transformação, não estimula o questionamento, o que torna os alunos cada vez mais passivos e despreparados para as mudanças inevitáveis da sociedade. Essas escolas não ensinam conceitos que serão relevantes para a vida do aluno, mas prepara de modo geral, pessoas cada vez mais superficiais, não se ensina a pensar, a tomar decisões importantes [8].

A contextualização no ensino de Química tem sido discutida no meio acadêmico como uma das alternativas para modificar o processo de ensino e aprendizagem. Segundo Gaia et al [9], o ensino contextualizado é motivador do aprendizado, pois chama a atenção dos estudantes e facilita a articulação de raciocínio relacionando conceitos trabalhados com aqueles conhecidos ou já observados na natureza e no dia a dia. Porém, contextualizar não é citar exemplo do cotidiano, mas sim, promover a integração entre conhecimentos científicos e o contexto em que o aprendiz convive, contribuindo para que esta relação favoreça a solução de problemáticas reais.

Para que a qualidade do ensino de Química melhore, se faz necessário adotar uma nova metodologia que esteja centrada em alguns princípios básicos. Dentre eles a necessidade de que o ensino esteja adequado à realidade econômica, política e social do meio onde se insere a escola, 
bem como a de executar experimentos que tenham como resultados dados observados na realidade da vida cotidiana [10].

Nos documentos oficiais, como a Lei de Diretrizes e Bases da Educação Nacional (LDBEN, 1996) [11] e nas avaliações realizadas pelo Ministério da Educação (MEC) [12], como o Exame Nacional do Ensino Médio (ENEM) [13], a contextualização do ensino é defendida como forma de promover uma educação voltada para o exercício da cidadania, pois favorece a autonomia e a capacidade dos alunos de participarem de forma crítica na resolução de problemas sociais presentes no cotidiano.

A seleção dos temas a serem trabalhados, de acordo com uma visão contextualizada do ensino, devem considerar fatos e fenômenos vivenciados pelos alunos e serem somados ao conhecimento científico da disciplina. Para facilitar os aspectos do conhecimento químico, a abordagem temática deve relacionar uma Situação de Estudo (SE), que introduz os conteúdos químicos a serem ensinados [14].

A combinação entre a necessidade do estudante de se apropriar do conhecimento científico, para atuar como cidadão, com a proposta de uma metodologia que envolva o uso de Situações de Estudo (SE), atrelados a pesquisa dos conteúdos na Web 2.0, pode estimular o aprendizado da disciplina. No entanto, não se deve excluir a mediação do professor cuja importância reside, principalmente, na condução e aprimoramento da pesquisa científica.

A inserção das tecnologias da informação e da comunicação (TIC), no ensino- aprendizagem de química, ultrapassa o tecnicismo e vai além da repetição de conceitos pelo estudante. Logo, não basta a inclusão do computador nas aulas é preciso verificar se os propósitos de interatividade e de construção do conhecimento estão sendo desenvolvidos.

As pessoas desenvolvem-se e aprendem mais quando estão inseridas num processo coletivo de aprendizagem. Nessa condição, elas compartilham significados e representações comuns, comunicam e discutem os seus pontos de vista, examinam e aperfeiçoam as suas ideias e, ainda, podem estabelecer o diálogo multidimensional acerca das questões colocadas, seja revisando, modificando ou contrapondo soluções e alternativas [15].

A postura do professor, que exige a educação deste novo tempo, deve estar relacionada também com a busca de ferramentas inovadoras para alterar o modo de ensinar e aprender. O planejamento das aulas deve ser modificado, para que a aquisição do conhecimento através da pesquisa, envolva a possibilidade do aluno analisar criticamente as informações que são apresentadas. Sendo assim, a pesquisa desenvolvida a partir da sala de aula precisa ser vista, entendida e praticada como uma metodologia capaz de construir o conhecimento. Além disso, o ambiente de pesquisa também exige outros fatores como um argumento crítico por parte do leitor. E ainda, para trabalhar com o debate em sala de aula torna-se fundamental exercitar o diálogo crítico, construído pelo exercício da leitura, da escrita e da argumentação, já que não há pesquisa sem leitura, escrita, argumento ou diálogo.

A Situação de Estudo (SE) como metodologia de ensino permite articular uma situação real e científica com o que acontece no cotidiano, onde os alunos contribuem com suas concepções, possibilitando aos professores identificar as dificuldades que são expressas oralmente e por escrito, conforme sugere Galiazzi [16]:

A sala de aula se resume em torno de questionamentos reconstrutivos de conhecimentos já existentes. Pressupõe um conjunto de princípios: questionamento reconstrutivo; argumentação competente e fundamentada; crítica e discussão permanentes a partir de produções escritas dos participantes, tipo de envolvimento em que os participantes se assumem sujeitos de suas produções, superando-se dessa forma a aula copiada e atingindo-se o aprender com autonomia e significado. 
A SE passou a ser refletida, como uma metodologia de ensino-aprendizagem no ano de 2000 através de estudos do Grupo Interdepartamental de Pesquisa Sobre Educação em Ciências (Gipec) da Universidade Regional do Noroeste do Estado do Rio Grande do Sul (Unijuí), sendo depois apresentada como uma proposta de pesquisa:

[...] conceitualmente rica, identificada nos contextos de vivência cotidiana dos alunos fora da escola, sobre a qual eles têm o que dizer e em cujo contexto, eles sejam capazes de produzir novos saberes, expressando-lhes significados e defendendo seus pontos de vista. [17].

Com as atividades e as vivências, oriundas da interação com os diferentes sujeitos, a SE ajuda a formar professores pesquisadores e alunos reflexivos e desacomodados, visto que os conteúdos não são prontos e acabados gerando sempre a necessidade da pesquisa e da reformulação. Maldaner [17], defende que a SE pode configurar um projeto de estudo, com duração de um trimestre ou bimestre, contendo as seguintes características:

[...] contemplar um número relativamente pequeno de conceitos centrais sendo estes sempre representativos da disciplina, compondo uma totalidade para cada disciplina e para o conjunto delas; [...] transacionar apenas significados iniciais para conceitos que aparecem pela primeira vez, podendo evoluir no desenvolvimento das SEs; estimular a produção criativa e coletiva dos estudantes sobre o entendimento da situação estudada como uma totalidade; [...] permitir que sejam significados os conhecimentos científicos contemporâneos, uma decorrência natural quando se estuda uma situação concreta e as soluções tecnológicas atuais. [18].

Há décadas, a experimentação no ensino de ciências é defendida por diferentes pesquisadores. $\mathrm{O}$ argumento principal, envolve o uso desse recurso pedagógico para apoiar a construção de conceitos, mas com objetivos claros como: demonstrar um fenômeno, testar hipóteses, desenvolver algumas habilidades, entre outros. No entanto, na maioria das vezes, as atividades de laboratório são orientadas por roteiros que resumem técnicas, como "receitas de bolo", onde os alunos seguem cada passo que o docente descreve. Esse ensino não envolve o raciocínio nem o questionamento, mas apenas distorce a atividade científica.

Uma alternativa para trabalhar com a experimentação, consiste em introduzir SE através do envolvimento dos alunos por uma ótica contextualizada dos conteúdos, visto que, as atividades experimentais representam um excelente recurso didático para a construção do conhecimento, pois favorece o caráter investigativo e a capacidade de tomada de decisão. Além disso, colabora para a formação do pensamento crítico, essencial para a construção da cidadania.

A elaboração do conhecimento científico apresenta-se dependente de uma abordagem experimental, não tanto pelos temas de seu objeto de estudo, os fenômenos naturais, mas fundamentalmente porque a organização desse conhecimento ocorre preferencialmente nos entremeios da investigação [19].

O emprego de SE nas aulas experimentais é um elo importante, entre o dia a dia do aluno e o conteúdo programático. A discussão de questões envolvendo os contextos histórico, político, social e ambiental, enfatiza a contextualização das atividades e possibilita a relação entre a ciência, a tecnologia e a sociedade.

Segundo Giordan [19], a experimentação pode ser caracterizada por duas formas: a ilustrativa e a investigativa. A experimentação ilustrativa é mais fácil de ser orientada, pois preocupa-se somente em demonstrar conceitos já discutidos, sem muita problematização ou discussão dos resultados. Em contrapartida, a investigativa discute conceitos e procura obter informações que reforcem uma discussão, reflexão, ponderação ou explicação, para que o aluno compreenda os 
conceitos e possa pensar e falar por meio da ciência. Sendo assim, a experimentação investigativa se aproxima mais das ideias da pedagogia problematizadora de Paulo Freire.

Com a proposta de facilitar a adaptação das ideias de Freire para o dia a dia da sala de aula, Delizoicov [20,21,22] estruturou três etapas pedagógicas distintas: a problematização inicial, a organização do conhecimento e a aplicação do conhecimento. A problematização inicial, apresenta situações reais que os alunos presenciam e que estão envolvidas com temas a serem discutidos. Na segunda etapa, os conhecimentos que precisam ser compreendidos devem ser estudados de forma sistematizada, ou seja, para desempenhar papel formativo e construtivo na apropriação crítica dos conhecimentos. E finalmente, a última etapa que serve para capacitar os alunos na utilização do conhecimento que vem sendo apreendido.

A atividade experimental problematizadora deve propiciar aos estudantes a possibilidade de realizar, registrar, discutir com os colegas, refletir, levantar hipóteses, avaliar as hipóteses e explicações, discutir com o professor todas as etapas do experimento. Essa atividade deve ser sistematizada e rigorosa desde a sua gênese, despertando nos alunos um pensamento reflexivo, crítico, fazendo os estudantes sujeitos da própria aprendizagem. Para tanto, se acredita que a escrita é um aspecto fundamental [23].

\section{MATERIAL E MÉTODOS}

O projeto intitulado "A importância do estudo das Reações Químicas para a prática cidadã", desenvolvido com os alunos do nono ano do ensino fundamental, em uma escola pública do interior de Sergipe, envolveu 21 aulas durante sete semanas e contou com a participação de 34 alunos do ano letivo de 2014. Apesar do colégio estar localizado na zona urbana da cidade, muitos dos estudantes não residem próximo e necessitam de transporte para estar em sala de aula. A turma é heterogênea, sendo constituída de indivíduos que trabalham no cultivo da cana de açúcar e em atividades rotineiras da agricultura e pecuária, outros que repetiram a série e tem idade para cursar a Educação de Jovens e Adultos (EJA).

A separação do projeto em etapas, permitiu organizar o trabalho acadêmico e motivar o grupo para as fases seguintes. Na etapa 1, analisou-se os conhecimentos prévios dos alunos, através do uso de quatro perguntas relacionadas com o tema do projeto, com isto esperávamos verificar qual impressão os meninos e meninas tinham sobre o tema para, futuramente discutir alternativas de estudo sobre contextualização.

Na segunda etapa, proporcionamos a apresentação do vídeo didático: “Aí tem Química, Reações Químicas" disponível no You Tube e produzido pela Pontifícia Universidade Católica do Rio de Janeiro (PUC-RJ), cujo objetivo foi exemplificar algumas reações químicas importantes no cotidiano, mas que nem sempre são observadas. A contextualização, que envolve a solução de problemas, foi discutida através das situações que envolveram as cenas. Os alunos puderam perceber a importância de entender não só como uma reação acontece, mas como propor alternativas para questões do seu cotidiano.

Na etapa 3, trabalhou-se com a caracterização da Simbologia usada nas Equações Químicas e com discussões sobre a classificação das Reações Químicas, em função da complexidade das substâncias envolvidas. A preocupação foi relacionar o aspecto cientifico das reações químicas, com a experimentação de forma que o aprendiz perceba a necessidade de usar a linguagem química para expressar os fatos experimentais.

$\mathrm{Na}$ etapa número 4, houve a apresentação do vídeo didático: "Grupo Loucos por Química Reações Químicas, partes 1 e 2", disponível no You Tube e com produção da Rede Cultura de Televisão. O uso da internet, na escola e a apresentação da atividade em grupo permitiu demonstrar algumas formas de pesquisa, que devem ser usadas para responder a questões e dúvidas sobre o projeto.

Finalmente na etapa 5, com a utilização de um texto científico, retirado da revista Scientific American Brasil (O Sequestro de Carbono Salvará o Carvão Limpo?), foi proposta a leitura, a 
discussão em grupo e a interpretação do texto em função de questões apresentadas. Neste ponto, a situação de estudo permitiu relacionar todas as perspectivas de ensino propostas no projeto. A partir da análise do texto relacionamos a contextualização, com levantamento da questão ambiental; da experimentação, com as reações químicas de combustão e que produzem gás carbônico; a pesquisa na Web 2.0, para encontrar alternativas ao uso de fontes de energia que eliminam $\mathrm{CO}_{2}(\mathrm{~g})$.

Os experimentos, para potencializar o aprendizado e reforçar o que foi apresentado em cada etapa, proporcionaram aos alunos ter contato com fenômenos só observados durante as reações químicas, como o desprendimento gasoso, a mudança de coloração das soluções e o estado de agregação dos materiais.

No experimento 1, promovemos a reação das soluções dos ácidos sulfúrico, clorídrico, fosfórico e acético com barras metálicas de zinco, magnésio, cobre e ferro (na forma de limalha). $\mathrm{O}$ experimento 2, com o intuito de analisar a velocidade de algumas reações, aconteceu com pastilhas de bicarbonato de sódio (inteira e fracionada), para reagir com os ácidos sulfúrico e clorídrico (fortes) e depois, com ácido acético e fosfórico (fracos). Já, o experimento 3, promoveu-se a titulação de uma solução de ácido clorídrico com o hidróxido de sódio, onde o indicador fenolftaleína foi adicionado para demonstrar o fim da reação de neutralização.

Os dados foram coletados através da aplicação de questionários fechados, onde os alunos responderam questões para verificar seus conhecimentos prévios, impressões sobre os vídeos didáticos e as observadas no experimento.

O objetivo desse trabalho foi desenvolver experimentos simples em sala de aula, com o suporte da contextualização e usando situações de estudo (SE) investigativas, para explicar e chamar a atenção do estudo das reações químicas, assim como, de inserir os alunos na cultura científica. Como referencial teórico foi trabalhado as visões de Delizoicov [20], Maldaner [17] e Giordan [19], onde a contribuição das conclusões desses pesquisadores, em diferentes produções cientificas, foi importante para definir o rumo da pesquisa. A análise de dados seguiu as propostas de Galiazzi [16], que se adaptou de forma satisfatória a pesquisa feita através de questionário fechado.

Os sujeitos da pesquisa foram identificados por uma letra "S" maiúscula e seguida de um número, portanto o sujeito 1 foi escrito com S1 e assim, de forma sucessiva para os outros componentes. Foi elaborado um termo de concordância (livre consentimento) e enviado aos responsáveis, daqueles menores de idade, com a explicação do contexto e a garantia do uso das respostas somente nessa pesquisa. Não houve recusa na participação.

\section{RESULTADOS E DISCUSSÃO}

O quadro abaixo, demonstra as perguntas propostas na etapa 1 , onde foi verificado os conhecimentos prévios dos estudantes sobre Reações Químicas.

Quadro 1: Questões propostas na pesquisa

\begin{tabular}{l}
\hline Questão 1: Explique na sua opinião, como ocorre uma reação química? \\
\hline Questão 2: Descreva alguma reação química que ocorra no seu dia a dia? \\
\hline Questão 3: Cite e procure explicar algum efeito observado quando acontece uma reação \\
química. \\
\hline Questão 4: Você já ouviu falar de reaçôes de oxi-redução ou redox? Dê exemplo. \\
\hline
\end{tabular}

As questões foram respondidas de forma simplista (A reação para obter "inhami cozinhado"; A reação é formada quando as "substâncias" "explode") e os alunos destacaram somente aquilo que era trazido com eles, a partir de suas concepções prévias. Acreditamos que estas visões estejam consolidadas pela vivencia com saberes passados de geração para geração, mas que reproduzem o fato observado sem ter aspecto cientifico relacionado. Portanto, esta mudança de concepção implica num grande desafio que é de apresentar a ciência/química de forma a modificar estas ideias.

Por se tratar de uma turma heterogênea, as respostas não foram satisfatórias. Poucos alunos tiveram a seriedade para completar a tarefa, deixando de responder ou sendo breve na escrita. No entanto, foi possível separar,entre os dados coletados as intervenções a seguir: 
Quadro 2: Respostas de sujeitos sobre as questões propostas

S1: questão 2 - Sim. A queima do palito de fósforo;

S2: questão 2 - Sim. A reação para obter "inhami cozinhado";

S3: questão 1 - A reação é formada quando as "substâncias" "esplodem";

S4: questão 1 - Uma reação química acontece quando moléculas se "abrem" e "fexam";

S4: questão 3 - Quando a vela tá pegando fogo tem uma "fumaça" negra saindo da vela;

S5: questão 3-O sabonete que forma espuma com a água;

S6: questão 4-Sim. A reação que forma ferrugem;

S7: questão 4 - Sim. A reação do ovo "cozinhado";

Nas questões respondidas pelos 34 sujeitos envolvidos no projeto, cuja ideia principal era recolher suas impressões iniciais (conhecimentos prévios) sobre as reações químicas e sua relação com o dia a dia, mas também com o que ele possa ter recebido como informação dos professores de ciências durante as séries iniciais do ciclo fundamental, foi importante para concluir que: 1) o aluno que chega ao último ano do ensino fundamental, escreve mal e interpreta mal o que lê, o que pode ser evidenciado pelas respostas dos sujeitos 2 (S2), 3 (S3) e 4 (S4); 2) a escrita não segue uma sequência de raciocínio, as ideias estão desconectadas do contexto, característica do sujeito 4. Nesse exemplo, foi fácil perceber a dificuldade encontrada em ordenar suas percepções; 3) a ideia simplista dos alunos e a forma tradicional de ensino, tem dificultado o aprendizado dos conteúdos; o conhecimento científico, inserido no conteúdo da disciplina, nem sempre é percebido pelo estudante de forma integral. As respostas a questão 4, por diferentes sujeitos, demonstra a necessidade de incentivar a leitura científica e a interpretação dos fatos, principalmente, pela mediação do professor.

$\mathrm{Na}$ etapa 2, a apresentação do vídeo foi seguida de discussão e debates sobre as possíveis reações químicas, que são observadas durante um dia inteiro de atividades de um cidadão comum. Foi possível também discutir sobre reações de combustão. Além disso, os alunos foram incentivados a selecionar informações sobre combustíveis fósseis e alternativos. Com os manuscritos recolhidos dos grupos, ampliou-se a discussão através da reflexão sobre o plantio e o corte de cana de açúcar para a fabricação de álcool combustível. Por ser tratar de situações, que estão mais próximas da realidade do aluno, como a problemática da cana, os meninos e meninas se envolveram mais nas discussões e participavam relatando suas experiências com a atividade. A questão social, que envolve a safra da cana e que deixa seus pais desempregados, apareceu várias vezes o que resume um drama que deixou marcas profundas e difíceis de apagar.

Com a seleção dos conteúdos, orientada pelo professor e seguida na sala de informática da unidade escolar, os alunos ao serem informados da necessidade de confeccionar uma pesquisa manuscrita, com introdução, desenvolvimento/importância e conclusão, sobre combustíveis fósseis, alternativos e o etanol, demonstraram interesse e procuraram cumprir a tarefa. Com os dados selecionados, os indivíduos terminaram a pesquisa em casa, sozinhos ou em grupo. Percebeuse, uma motivação dos sujeitos no cumprimento da tarefa. Os grupos não só interagiam entre si, mas buscavam completar as informações sugeridas pelos colegas.

A etapa 3, com a classificação das Reações Químicas em função da complexidade das substâncias envolvidas, foi conduzida com recurso multimídia em programa Power Point. A finalidade desta ação foi criar uma espécie de diálogo entre a realidade científica e a cotidiana, destacando a importância da interação entre química e sociedade. Buscou-se desmontar a visão dinâmica da ciência, com relação dos fatos históricos envolvidos com o ensino de reações químicas. Para isso, a apresentação contou com exemplos de fenômenos químicos observados na comunidade, como por exemplo, a transformação da cana de açúcar em combustível. Novamente, a discussão que envolve a atividade foi levantada. A produção de álcool, em detrimento do açúcar, indicou para os alunos a questão do mercado internacional que demanda sempre mais e mais produto. Estes insistiram em afirmar que seus pais, nem sabiam que a usina que eles trabalham cortando cana produzia também álcool. A partir de uma visão construtivista na qual o conhecimento não é transmitido, mas construído ativamente pelos indivíduos e aquilo que o sujeito já sabe influencia na sua aprendizagem (MORTIMER e MACHADO, 2010), foi observado uma maior aceitação da aula teórica. Os estudantes estavam mais participativos e relatavam fatos que ocorreram na 
comunidade (como a queima de uma área além do limite do cultivo de cana, em função do fenômeno da "queimada da cana") e, alguns até continuaram a perguntar mesmo após o término do horário da aula.

A condução do projeto teve continuidade na etapa 4, com apresentação de outro vídeo didático também retirado do You Tube e do "Grupo Loucos por Química, intitulado Reações Químicas, partes 1 e 2". A finalidade dessa etapa foi a de dar continuidade a classificação das reações químicas, vista na aula anterior, e ressaltar o conhecimento de princípios em contraposição ao conhecimento ritualístico. $\mathrm{O}$ uso de um relato (Uma reação química acontece quando moléculas se "abrem" $e$ "fexam"), permitiu discutir de forma cientifica o que ocorre durante uma reação. Então, o saber fazer dos procedimentos foi substituído por processos explicativos com orientação para o entendimento do fenômeno físico-químico envolvido.

Com a mudança de foco de ensino, os alunos não só percebem a atualidade e importância do que estão estudando, mas também, deixam de "decorar" aquilo que dificilmente terá relação com sua vida. Sendo assim, a ideia de aprender o mecanismo que envolve uma reação entre substâncias simples e compostas, foi substituída pela importância de entender a composição das reações de combustão, onde destacou-se que sem oxigênio (comburente) não há queima de combustível (cana). Muitos alunos, comentaram que a presença da água ou da espuma dos extintores de incêndio, impediriam as reações de queima/combustão. Foi proposto aos grupos, uma pesquisa sobre "queimada controlada", em plantações empresariais.

A utilização de texto científico, "O Sequestro de Carbono Salvará o Carvão Limpo?", foi separado para discussão com duas finalidades. A primeira e mais importante, envolve a tentativa de oportunizar aos alunos a possibilidade de se expressarem nas discussões em grupo. Com uso da linguagem cotidiana e pela análise do discurso científico do texto, espera-se que o aluno possa se apropriar da linguagem científica no seu discurso no ambiente em que vive. A discussão, leitura e explicação do texto científico tem a função de implementar uma perspectiva dialógica em sala de aula, que é necessária para contemplar a visão de mundo implícita na linguagem cotidiana do aluno.

Apesar da discussão do texto e da mediação do conteúdo pelo professor, foi possível observar que para o sujeito se apropriar do discurso cientifico é necessário que o professor trabalhe com mais projetos que envolvam esse contexto. Além disso, percebeu-se a necessidade de criar situações que possam ser confeccionados projetos interdisciplinares. Esses projetos podem ser entre ciências do mesmo grupo, como química, física e biologia, ou entre disciplinas de grupo diferentes. No entanto, o planejamento das aulas deve ser cuidadoso para possibilitar uma maior interação entre os diferentes campos do conhecimento.

A última etapa do projeto envolveu a experimentação. Mesmo não sendo uma escola com espaço apropriado para uma aula experimental, as atividades foram desenvolvidas na sala de aula e possibilitaram aos alunos ter o primeiro contato com uma "aula de laboratório". Entende-se que a ausência dos fenômenos químicos nas salas de aula, atrapalha o aprendizado da química. É preciso combinar teoria e experimento com pensamento e realidade, ainda que o sujeito não seja capaz de conhecer por completo a teoria cientifica, para interpretar determinado fenômeno ou resultado de uma experiência, ele vai usar suas teorias implícitas e as suas ideias de senso comum, para tentar entender e formular perguntas e respostas. No ensino tradicional, o experimento é separado da teoria e serve apenas como comprovação. Os procedimentos são apresentados como "receita de bolo" levando a um resultado que os alunos já conhecem, e que acabam por ser forjados quando em desacordo com a teoria.

A maioria das escolas do estado de Sergipe não dispõem de laboratório. Em algumas delas o espaço disponível serve à outras finalidades, como por exemplo, depósito de livros. Não há material e nem reagentes para as práticas experimentais. Além disso, muito dos professores não são preparados para o exercício da profissão. Alguns oriundos do concurso do magistério de 2012, se apresentam descontentes com a profissão e usam a atividade como trampolim para outras oportunidades profissionais. Esses fatos contribuem para a aula tradicional, onde a preocupação do discente é montar uma espécie de apostila com as orientações que são seguidas pelos alunos. Não há sequer um planejamento das aulas.

Os experimentos realizados foram separados em três estágios, de acordo com a complexidade das substâncias envolvidas. No estágio 1, a preocupação foi reagir barras dos metais zinco, magnésio, cobre e ferro com diferentes soluções ácidas (sulfúrico, clorídrico, fosfórico e acético) e 
ainda, reagiu-se ácido sulfúrico com ferro em barra e na forma de limalha. No estágio 2, com comprimidos de antiácidos foi verificada a velocidade das reações em água e na presença de ácido acético, além do uso de comprimidos inteiros e em pedaços. E finalmente, no estágio 3 foi trabalhado as reações de neutralização, envolvendo a titulação ácido-base, com soluções de ácido clorídrico e hidróxido de sódio.

Através das observações dos fenômenos ocorridos nos experimentos, os alunos apresentaram uma espécie de relatório, contendo introdução, materiais e métodos, observações, conclusão e bibliografia. $\mathrm{O}$ entusiasmo e as perguntas feitas pelos alunos demonstraram claramente a importância do trabalho experimental na construção do conhecimento. A divisão da aula experimental em estágios, que a princípio poderia prejudicar o ensino-aprendizagem não foi um obstáculo. As perguntas orientadas durante cada experiência eram acompanhadas de respostas mais sofisticadas e de tentativas de participação nos experimentos. As reações do estágio 1 foram usadas também, para reforçar as perguntas feitas durante o questionário proposto na Etapa 1 do projeto. Foi percebido que houve uma maior elaboração das respostas e uma mudança no discurso científico. O sujeito S3, que respondeu a questão 1 ("Explique na sua opinião, como ocorre uma reação química?") de forma simplista, no início do projeto (A reação é formada quando as "substância" "esplode"), com a aplicação do questionário após a aula experimental, elaborou a seguinte resposta: "Uma reação química pode ocorrer de diferentes formas, com substâncias sólidas, líquidas e liberando gases. Nas reações de combustão, como por exemplo, a do gás de "cosinha" a reação química só inicia com ajuda de outra substância, o fósforo"...

Apesar de alguns erros conceituais e uma interpretação incompleta dos fatos, observa-se um avanço na escrita e reflexão apresentada. Pode-se dizer, que houve uma mudança da visão simplista para outra que está mais próxima daquela que envolve a visão científica.

O estágio 2, contemplou o aspecto que envolve a cinética das reações. Os comprimidos de antiácido tiveram a velocidade de decomposição cronometrada, seja na presença de água ou ácido acético. Comparou-se também as velocidades de decomposição com os comprimidos inteiros e triturados. Ainda, verificou-se o efeito da temperatura na velocidade da reação. Com o uso de um termômetro, os alunos concluíram que na presença de água quente (cerca de 500C) a reação ocorre mais rapidamente. Nesse estágio, usou-se o livro didático para responder a questões propostas sobre o assunto. Também foi possível observar, um maior envolvimento dos alunos para responder as questões propostas pelo livro didático.

O estágio 3, onde trabalhou-se com reações de neutralização total a atividade experimental foi basicamente demonstrativa. Como necessita de material específico para ocorrer, a titulação ácidobase foi reproduzida pelo professor e cada grupo, a partir das observações de aula e das orientações sugeridas, buscou responder as perguntas que envolvem a importância desse procedimento experimental nas indústrias químicas. Como nas outras atividades propostas, os alunos se envolveram e buscaram interagir para cumprir com o pedido do professor. A pesquisa em grupo, de forma colaborativa, permitiu que os alunos se envolvessem nos fenômenos químicos, nas teorias e nas representações dos fatos.

\section{CONCLUSÃO}

A escolha da experimentação como estratégia de ensino-aprendizagem, demonstrou ser uma metodologia viável no ensino de Química. As aulas práticas proporcionaram grande motivação nos alunos, o que foi percebido através do aumento da participação nas atividades em sala de aula. Os experimentos favoreceram a construção do conhecimento, estimularam o caráter investigativo, a tomada de decisão e a aprendizagem colaborativa nos alunos.

A contextualização das atividades, mediante o emprego de situações de estudo (SE), possibilitou a correlação entre os conteúdos da Química e o cotidiano dos alunos. Com isso, as discussões de questões que envolvem a relação entre ciência, tecnologia, sociedade e ambiente (CTSA) colaboram para a formação de um cidadão com mais embasamento cientifico para se tornar crítico.

A contextualização, desenvolvida através de SE, promove debates em sala de aula e possibilita ao aluno compreender o significado do que se estuda, deixando de lado a memorização de nomes e fórmulas que dificultam o processo de ensino/aprendizagem e tornam as aulas de Química 
desgastantes. Assim, o uso de um tema social que está totalmente inserido no dia a dia do aprendiz, dá sentido ao conteúdo científico e é eficaz para ajudar na compreensão dos conceitos químicos.

A evolução da escrita dos alunos foi percebida durante as etapas do estudo, mas com a análise e interpretação de texto, da última etapa, ficou claro a evolução na escrita da língua portuguesa. Para dar continuidade a leitura cientifica e a apropriação da linguagem, não se deve delegar essa tarefa somente aos professores de línguas e literaturas, mas todo o corpo docente deve "abraçar" essa ideia e preparar atividades que incentivem a leitura e a escrita, seja cientifica ou de senso comum.

A escolha da SE, como proposta de ensino, permitiu situar a atividade em um contexto real e rico de conceitos, que facilitou o entendimento dos fatos científicos e contribuiu para a formação dos estudantes, mas também pode ajudar na transformação do ensino pela inserção de uma situação real vivida pela comunidade, o que se diferencia dos conteúdos prontos e trabalhados exaustivamente, nos livros didáticos pelo método tradicional de ensino.

\section{REFERENCIAS BIBLIOGRÁFICAS}

1. Freire P. Pedagogia do Oprimido. Rio de Janeiro: Paz e Terra, 1987.

2. Gadotti M. Convite à Leitura de Paulo Freire. Editora Scipione.1989.

3. Mortimer EF.; Machado, A. H.; Romanelli, L. I. A proposta curricular de química do Estado de Minas Gerais: fundamentos e pressupostos. Química Nova, São Paulo, v. 23, n. 2, p. 273-283, 2000. 4. Batinga VTS, Teixeira FM. O que pensam os professores de química do ensino médio sobre o conceito de problema e exercício. In: VII ENPEC- Encontro Nacional de Pesquisa em Educação em Ciências, 2009, Florianópolis. Anais do VII ENPEC. Florianópolis: ABRAPEC, 2009.

5. Chassot A. Educação consciência. Santa Cruz do Sul: EDUNISC, 2003.

6. Budel GJ. Ensino de Química na EJA: Uma proposta metodológica com abordagem do cotidiano. Universidade Federal do Paraná, p.1-21, 2008.

7. Wiley D. (2000) The instructional use of learning objects. On-line version. Disponível em: <http://reusability.org/read/>. 2000. Acesso em: 20/12/2014.

8. Fernandes MM.; Silva, M. H. S. O trabalho experimental de investigação: das expectativas dos alunos às potencialidades no desenvolvimento de competências. Revista Brasileira de Pesquisa em Ensino de Ciências, v. 4, n. 1, 2004. p. 45-58.

9. Vicari R M. et al. Proposta brasileira de metadados para objetos de aprendizagem baseados em agentes (obaa). 2010.

10. Da Silva JR, MELO MR. Ensinando sobre sabão e detergente por aprendizagem colaborativa através de uma mídia social, XVII Encontro Nacional de Ensino de Química (ENEQ), 2014, p. 3. 11. BRASIL, Diretrizes Curriculares Nacionais Gerais da Educação Básica. Brasília: MEC/SEF, 2013.

12. BRASIL. Secretaria de Educação Média e Tecnológica. PCNEM+ Ensino Médio: Orientações Educacionais complementares aos Parâmetros Curriculares Nacionais. Linguagens, códigos e suas tecnologias. Brasília, DF: Ministério da Educação/Secretaria de Educação Média e Tecnológica, 2002.

13. BRASIL. Ministério da Educação/ Instituto Nacional de Estudos e Pesquisas Educacionais: Exame Nacional do Ensino Médio. Brasília, DF, 2011.

14. Kato DS, Kawasaki CS. As concepções de contextualização do Ensino em documentos curriculares oficiais e de professores de ciências. Ciências e Educação, São Paulo, v. 17, n.1. p. 3550, 2011.

15. Torre TZ, Amaral SF. do. Aprendizagem Colaborativa e Web 2.0: proposta de modelo de organização de conteúdos interativos. ETD-Educação Temática Digital, v. 12, p. 49-72, 2011.

16. Galiazzi M C, Moraes R. Educação pela pesquisa como modo, tempo e espaço de qualificação da formação de professores de ciências. Ciência \& Educação, v. 8, n. 2, p. 237-252, 2003.

17. Maldaner OA. Situações de estudo no ensino médio: nova compreensão de educação básica. In: Nardi R. (Org.). A pesquisa em ensino de ciências no Brasil: alguns recortes. São Paulo: Escrituras, 2007a. p. 239-254.

18. Maldaner OA, Zanon LB. Situação de Estudo: uma organização do ensino que extrapola a formação disciplinar em Ciências. In: Moaraes, R.; Mancuso, R.(Org.). Educação em Ciências Produção de Currículos e Formação de Professores. Ijuí: Ed. Unijuí, 2004. p. 43-64. 
19. Giordan MO papel da Experimentação no Ensino de Ciências: Química Nova na Escola, São Paulo, n. 10, p. 43-49, novembro, 1999.

20. Delizoicov D. Ensino de Física e a concepção freiriana de educação. Revista de Ensino de Física, v. 5, n. 2, p. 85-98, 1983.

21. Conhecimento, tensões e transições. 1991. Tese (Doutorado). Faculdade de Educação, Universidade de São Paulo, São Paulo, 1991.

22. ___ Problemas e problematizações. In: Pietrocola, M. (Org.). Ensino de Física: conteúdo, metodologia e epistemologia em uma concepção integradora. Florianópolis: UFSC, p. 125-150, 2005.

23. Francisco Jr W, Ferreira LHE, Hartwing DR. Experimentação Problematizadora: Fundamentos Teóricos e Práticos para a Aplicação em Salas de Aula de Ciências. In: Revista Química Nova na Escola, 2008, n. 30, p. 34-41. 